\title{
Autoimmune polyglandular syndrome type 2 and autoimmune hepatitis with thymoma-associated myasthenia gravis: case report
}

\author{
Hidefumi Inaba ${ }^{1 *} \mathbb{D}$, Hiroyuki Ariyasu ${ }^{1}$, Hiroshi Iwakura ${ }^{1}$, Chiaki Kurimoto ${ }^{1}$, Yoko Ueda ${ }^{1}$, Shinsuke Uraki ${ }^{1}$, \\ Ken Takeshima ${ }^{1}$, Yasushi Furukawa ${ }^{1}$, Shuhei Morita ${ }^{1}$, Yoshiaki Nakayama ${ }^{2}$, Takuya Ohashi ${ }^{3}$, Hidefumi Ito², \\ Yoshiharu Nishimura ${ }^{3}$ and Takashi Akamizu'
}

\begin{abstract}
Background: Autoimmune polyglandular syndrome type 2 (APS-2) is a rare and complex clinical entity, and little is known about its etiology and progression.

Case presentation: A 52-year-old woman with autoimmune hepatitis (AlH) and bronchial asthma was diagnosed with APS-2; autoimmune Addison's disease (AD), and Hashimoto's thyroiditis (HT), and she underwent prednisolone (PSL) treatment. Five months later, she presented ptosis and was diagnosed with thymoma-associated myasthenia gravis (MG). Thymectomy and PSL treatment with immuno-suppressants appeared to ameliorate $M G, A D, A I H, H T$, and bronchial asthma. HLA typing analysis revealed that the patient had susceptible HLA alleles to MG, AlH, and HT in a Japanese population.
\end{abstract}

Conclusions: This case suggests common endocrinological and autoimmune aspects of APS-2 and AlH with thymoma-associated MG, which are considered to be extremely rare complications.

Keywords: Autoimmune polyglandular syndrome type 2 (APS-2), Autoimmune Addison's disease, Hashimoto's thyroiditis, Autoimmune hepatitis, Thymoma-associated myasthenia gravis, Bronchial asthma

\section{Background}

Autoimmune polyglandular syndrome type 2 (APS-2) is a rare complex clinical entity. It is defined as autoimmune Addison's disease (AD) concomitant with autoimmune thyroid diseases such as Graves' disease and Hashimoto's thyroiditis (HT), and/or type 1 diabetes mellitus, in the absence of hypoparathyroidism [1]. The prevalence of APS-2 is $1.4-4.5$ per 100,000 and it most commonly affects middle-aged women [1].

Myasthenia gravis (MG) is a neuromuscular junction disease that is mostly associated with autoimmune antibodies, such as anti-acetylcholine receptor (AChR)-antibody (Ab) $[2,3]$. Autoimmune hepatitis $(\mathrm{AIH})$ is characterized by

\footnotetext{
* Correspondence: inaba@wakayama-med.ac.jp

${ }^{1}$ The First Department of Medicine, Wakayama Medical University, 811-1,

Kimiidera, Wakayama, Japan

Full list of author information is available at the end of the article
}

autoimmunity to hepatocytes with increase of antinuclear antibody (ANA) [4]. Co-existence of MG and AIH is rare $[3,5]$. Moreover, cases of APS-2 with thymoma-associated MG and AIH are extremely rare, and their common etiology has been unclear [1]. Here, we report a case of APS2 accompanied by thymoma-associated MG and AIH. We also examined the HLA of the patient, including diseasesusceptible allele.

\section{Case presentation}

A 52-year-woman was admitted to our hospital because of 3-month history of loss of appetite, fatigue, and 2month history of pigmentation of the oral mucosa and the tongue. She had been treated for bronchial asthma for 9 years by budesonide formoterol fumarate hydrate inhalation and oral theophylline. She had also had been 
diagnosed with $\mathrm{AIH}$ and had been taking azathioprine $(50 \mathrm{mg} /$ day) for 5 years.

She had no familial history of autoimmune disease. Her height was $144.5 \mathrm{~cm}$, and body weight was $57.0 \mathrm{~kg}$ (BMI: $27.3 \mathrm{~kg} / \mathrm{m}^{2}$ ). There was no apparent loss of body weight. Blood pressure was $88 / 63 \mathrm{mmHg}$. Her thyroid gland was firm and diffusely enlarged. In laboratory tests (Table 1), serum sodium and potassium levels were normal (under treatment of oral furosemide: $10 \mathrm{mg} /$ day), and eosinophilia and hypoglycemia were not observed.

Table 1 Laboratory data on admission

\begin{tabular}{llll}
\hline & Results & Unit & Normal range \\
\hline WBC & 3330 & $/ \mu \mathrm{L}$ & $(3500-9800)$
\end{tabular}

(Neutro 51.1\%, Eos 0\%, Baso 0\%, Lym 42.6\%)

\begin{tabular}{|c|c|c|c|}
\hline $\mathrm{Hb}$ & 12 & $\mathrm{~g} / \mathrm{dL}$ & $(12-15)$ \\
\hline Plt & $21.7 \times 104$ & $/ \mu \mathrm{L}$ & $(13-37)$ \\
\hline TP & 6.2 & $\mathrm{~g} / \mathrm{dL}$ & $(6.7-8.1)$ \\
\hline Alb & 3.4 & $\mathrm{~g} / \mathrm{dL}$ & $(3.9-4.9)$ \\
\hline AST & 35 & $I U / L$ & $(7-38)$ \\
\hline ALT & 14 & $\mathrm{IU} / \mathrm{L}$ & $(4-44)$ \\
\hline ALP & 262 & $I U / L$ & $(115-359)$ \\
\hline G-GTP & 19 & $\mathrm{IU} / \mathrm{L}$ & $(9-35)$ \\
\hline LDH & 157 & $\mathrm{IU} / \mathrm{L}$ & $(106-220)$ \\
\hline BUN & 13 & $\mathrm{mg} / \mathrm{dL}$ & $(8-20)$ \\
\hline $\mathrm{Cr}$ & 0.53 & $\mathrm{mg} / \mathrm{dL}$ & $(0.43-0.72)$ \\
\hline T-bil & 0.7 & $\mathrm{mg} / \mathrm{dL}$ & $(0.2-1.2)$ \\
\hline $\mathrm{Ca}$ & 8.9 & $\mathrm{mg} / \mathrm{dL}$ & $(8.8-10.1)$ \\
\hline$P$ & 3.2 & $\mathrm{mg} / \mathrm{dL}$ & $(2.7-4.6)$ \\
\hline $\mathrm{Na}$ & 137 & $\mathrm{mEq} / \mathrm{L}$ & $(135-145)$ \\
\hline K & 3.7 & $\mathrm{mEq} / \mathrm{L}$ & $(3.5-5.0)$ \\
\hline $\mathrm{Cl}$ & 101 & $\mathrm{mEq} / \mathrm{L}$ & $(98-107)$ \\
\hline$P G$ & 80 & $\mathrm{mg} / \mathrm{dL}$ & (70-109) \\
\hline $\mathrm{HbA1c}$ & 5 & $\%$ & $(4.6-6.2)$ \\
\hline ANA & 80 & $x$ & $(<40)$ \\
\hline ds-DNA & negative & & \\
\hline RNP & negative & & \\
\hline $\mathrm{Sm}$ & negative & & \\
\hline SS-A & negative & & \\
\hline SS-B & negative & & \\
\hline Scl-70 & negative & & \\
\hline C3 & 102 & $\mathrm{mg} / \mathrm{dL}$ & $(65-135)$ \\
\hline C4 & 19 & $\mathrm{mg} / \mathrm{dL}$ & $(13-35)$ \\
\hline \multicolumn{4}{|l|}{ Jrinary analysis } \\
\hline SG & 1.02 & & \\
\hline Protein & $(-)$ & & \\
\hline Occult blood & $(-)$ & & \\
\hline Sugar & $(-)$ & & \\
\hline
\end{tabular}

In endocrinological examinations (Table 2), serum cortisol level at 06:00 was remarkably decreased, $<1.0 \mu \mathrm{g} / \mathrm{dL}$ (normal range: 2.9-19.4) and plasma adrenocorticotropic hormone (ACTH) level was elevated, $800.0 \mathrm{pg} / \mathrm{mL}$ (normal range: 7.2-63.3). Adrenal cortex autoantibodies (ACA) were positive, $\times 40$ (normal range: $<\times 10$ ). Abdominal CT showed that bilateral adrenal glands were slightly atrophied (Fig. 1a). Based on clinical findings and endocrinological data, she was diagnosed with autoimmune AD. She also had HT. Her anti-thyroglobulin antibody (TgAb) was elevated, $231.9 \mathrm{IU} / \mathrm{mL}$ (normal range: <28.0) (Table 3). Ultrasonography examination showed diffusely enlarged thyroid gland, with coarse and hypoechogenic pattern. Both serum calcium level, 8.9 $\mathrm{mg} / \mathrm{dL}$ (8.8-10.1), and plasma intact PTH level, $31 \mathrm{pg} /$ dL (9.3-74.9) were normal (Tables 1, 2 and 3). Based on these findings, she was diagnosed with APS-2. In order to treat $\mathrm{AIH}$ and autoimmune $\mathrm{AD}$, PSL was considered to be better than hydrocortisone. Therefore, PSL (10 $\mathrm{mg} /$ day $)$ and fludrocortisone $(0.1 \mathrm{mg} /$ day $)$ were started for autoimmune $\mathrm{AD}$. The pigmentation of the oral mucosa and the tongue, the loss of appetite, the fatigue, and the hypotension disappeared within 3 months.

Five months after diagnosis of APS-2, she noticed ptosis in both eyes which worsened in the evening. There was no

Table 2 Endocrinological data on admission

\begin{tabular}{llll}
\hline & Results & Unit & Normal range \\
\hline TSH & 2.515 & $\mu \mathrm{UU} / \mathrm{mL}$ & $(0.35-4.94)$ \\
FT3 & 3.51 & $\mathrm{pg} / \mathrm{mL}$ & $(1.71-3.71)$ \\
FT4 & 0.93 & $\mathrm{ng} / \mathrm{dL}$ & $(0.70-1.55)$ \\
TRAb & $<1.0$ & $\mathrm{IU} / \mathrm{mL}$ & $(<2.0)$ \\
TgAb & 231.9 & $\mathrm{IU} / \mathrm{mL}$ & $(<28.0)$ \\
TPOAb & $<5.0$ & $\mathrm{U} / \mathrm{mL}$ & $(<16.0)$ \\
F & $<1.0$ & $\mu \mathrm{g} / \mathrm{dL}$ & $(2.9-19.4)$ \\
ACTH & 800 & $\mathrm{pg} / \mathrm{mL}$ & $(7.2-63.3)$ \\
PAC & 1.2 & $\mathrm{ng} / \mathrm{dL}$ & $(3.6-24)$ \\
PRA & 14 & $\mathrm{ng} / \mathrm{mL} / \mathrm{H}$ & $(0.2-3.9)$ \\
i-PTH & 31 & $\mathrm{pg} / \mathrm{d}$ & $\mathrm{L}(9.3-74.9)$ \\
ACA & 40 & $\times$ & $(<10)$ \\
GADAb & $<1.3$ & $\mathrm{U} / \mathrm{mL}$ & $(0-1.4)$ \\
IA-2Ab & negative & & \\
Urinary examination & & \\
free F & $<1$ & $\mu \mathrm{g} / \mathrm{day}$ & $(43-176)$ \\
GH & 0.6 & $\mathrm{ng} / \mathrm{mL}$ & $(0-2.1)$ \\
IGF-I & 39 & $\mathrm{ng} / \mathrm{mL}$ & $(78-213)$ \\
LH & 5.7 & $\mathrm{mlU} / \mathrm{mL}$ & $(1.7-11.2)$ \\
FSH & 7.9 & $\mathrm{mlU} / \mathrm{mL}$ & $(2.1-18.6)$ \\
E2 & 461 & $\mathrm{pg} / \mathrm{mL}$ & \\
PRL & 38 & $\mathrm{ng} / \mathrm{mL}$ & $(<15)$ \\
\hline
\end{tabular}




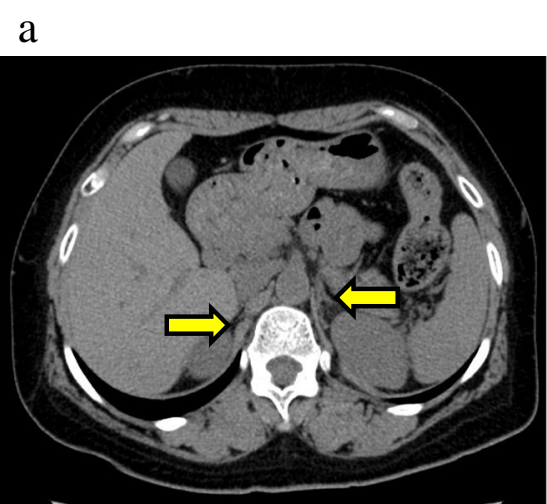

\section{b}

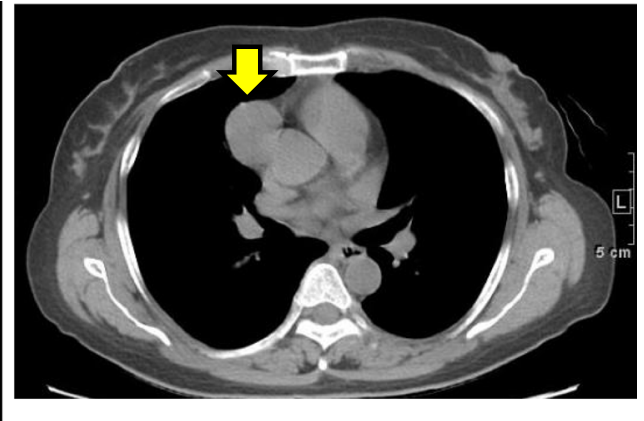

Fig. 1 a On an abdominal $C$, atrophy of the bilateral adrenal glands was seen (arrows). b A solid mass was seen in the anterior mediastinum (arrow) on a chest $C T$, suspected to be thymoma ( $34 \times 34 \mathrm{~mm}$ in size)

muscle weakness, dysarthria, or dysphagia. She was readmitted to hospital. On readmission, anti-AChR-Ab level was increased, $4.4 \mathrm{nmol} / \mathrm{L}$ (normal range: 0-0.3). Antititin antibody was not measured. The repetitive nerve stimulation test at $3 \mathrm{~Hz}$ of the right facial nerve revealed decremental response. On chest CT, an anterior mediastinal mass $(34 \times 34 \mathrm{~mm})$ was observed, which was suspected to be thymoma (Fig.1b). She was thus diagnosed with thymoma-associated ocular MG. Pyridostigmine treatment was begun, but due to adverse events including abdominal pain and skin rash, it was withdrawn. Since symptoms of the ocular MG were very slight, PSL (10 mg/ day) for autoimmune $\mathrm{AD}$ and ocular MG was continued. Azathioprine $(50 \mathrm{mg} /$ day) for AIH was continued by the hepatologist. Subsequently, total thymectomy was conducted. The surgical specimen of mediastinal mass

Table 3 Results of HLA typing test of the patient

\begin{tabular}{lll}
\hline HLA & Patient allele & $\begin{array}{l}\text { Susceptible autoimmune } \\
\text { disease (References) }\end{array}$ \\
\hline A & $11: 01 / 24: 02$ & \\
B & $39: 01 / 51: 01$ & \\
C & $07: 02 / 14: 02$ & AlH Ref [4]. Other APS-2 \\
DRB1 & $04: 05 / 11: 01$ & case Ref [6] \\
DRB3 & $02: 02$ & HT Ref [7], AlH Ref [4] \\
DRB4 & $01: 03$ & \\
DQA1 & $03: 03 / 05: 05$ & AlH Ref [4], MG Ref [8] \\
DQB1 & $03: 01 / 04: 01$ & \\
DPA1 & $01: 03 / 02: 02$ & MG Ref [8] \\
DPB1 & $02: 01 / 05: 01$ &
\end{tabular}

Footnotes:

HLA-DRB1*04:05, DRB4, and DQB1*04:01 for AlH ref. [4], DRB4 for HT ref. [7], and $\mathrm{DQB} 1{ }^{*} 03$ and $\mathrm{DPB} 1{ }^{* 02} 0201$ for MG ref. [8] were reported as disease-susceptible alleles

Konno, et al. reported a case of APS-2 similar to the current case; AD, HT and AlH with MG without thymoma and bronchial asthma who had HLA-A23, B52/ 62 , and DR11/15 ref. [6] exhibited thymoma: histological type B2, pT2, R0. After the thymectomy, PSL and immuno-suppressant treatment was continued (Fig. 2). The level of anti-AchR-Ab for MG then decreased. Ptosis also improved within 5-6 months. After 42 months, immuno-suppressant treatment was ceased, but even after 10 months, MG had not worsened. Normalized ACA levels $(<10)$ at 53 months might suggest improvement of AD or atrophy of the adrenal glands. Although serum levels of TgAb and anti-thyroperoxidase antibody (TPOAb) increased during the course, thyroid function stayed normal during the entire course, thus HT had not worsened.

Since multiple concurrent autoimmune diseases were seen, the patient underwent HLA typing tests. She had HLA-A*11:01/24:02, B*39:01/51:01, C*07:02/14:02, DRB 1*04:5/11:01, DRB3*02:02, DRB4*01:03, DQA1*03:03/ 05:05, DQB1*03:01/04:01, DPA1*01:03/02:02, and DP B1*02:01/05:01 (Table 3).

\section{Discussion and conclusion}

APS is divided into 4 types, and APS-2 with autoimmune $\mathrm{AD}$ and HT is referred to as Schmidt's syndrome [1]. Thymoma is reported in 15\% of cases of MG, and half of cases of thymoma have concomitant MG $[2,6]$. The prevalence of AIH in APS- 2 is reported to be $4 \%$, and MG in APS-2 is considered to be even more rare [3].

In the current case, based on the typical endocrinological findings, autoimmune AD and HT were diagnosed. The absence of hypoparathyroidism led to diagnosis of APS-2. Thymoma-associated MG concomitant with AIH and bronchial asthma was also observed. Although cases of APS-2 have been reported, to the best of our knowledge, cases of APS-2 with thymoma-associated MG are rare, and their complication with $\mathrm{AIH}$ and bronchial asthma has not been reported until now.

Multiple genetic and environmental factors seem to be associated with the development of APS-2, but its etiology is not understood [1]. In the current case, MG developed 


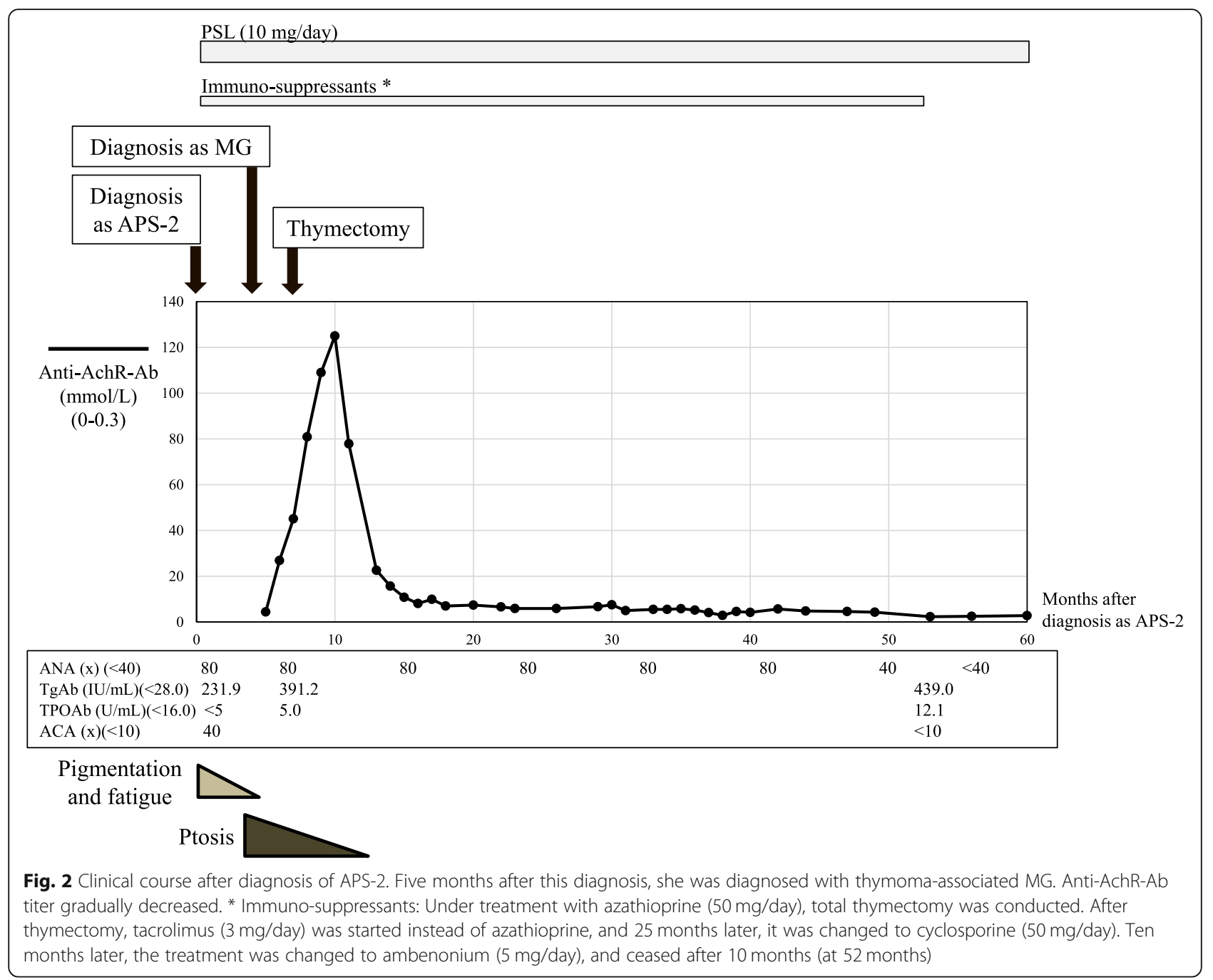

despite the patient receiving PSL and azathioprine therapy. The reason for this is unclear, but enlarged thymoma might affect the development of MG.

HLA has been reported to be a major genetic factor for APS-2. HLA-DR3/DR4 alleles or its haplotype are reported to be one of the large risk factors for APS-2 in Western people [1]. To date, however, predisposition of HLA alleles to APS-2 in Japanese has not been reported.

In Japanese cohorts, disease-predisposing alleles are as follows: HLA-DRB4 for HT [7], HLA-DRB1*04:05, DRB4 and DQB1*04:01 for AIH [4], and DQB1*03 and DPB1*02: 01 for MG [8]. All of these alleles were seen in the current case. Konno, et al. reported a case of APS- 2 similar to the current case; their patient had AD, HT and AIH with MG without thymoma and with no bronchial asthma but had HLA-A23, B52/62, and DR11/15 [9]. DR11 was also seen in the current case. Seker, et al. also reported a case of AD and MG with thymoma, but without HT or AIH [10]. They did not examine HLA typing. HLA typing test could be useful for patients with multiple autoimmune diseases to determine a common immunological factor. HLA typing test would reveal various disease-susceptible and diseaseprotective alleles. Thus, early prediction and intervention of the diseases may be possible, and such information could help patient care in the long-term.

Given that development of bronchial asthma is reported to be associated with HLA inheritance [11], concomitance of $\mathrm{AD}, \mathrm{HT}$, thymoma-associated MG, and possibly bronchial asthma, could be related to common HLA allele or haplotypes. Since autoantigen is presented on the surface of antigen-presenting cells with HLA-class I (cytotoxic effects of CD8+ T-cells) or HLA-class II (effector effects of CD4+ T-cells), common antigen may also be involved in multiple diseases. A common antigen among AD, HT, AIH, MG, and possibly bronchial asthma, may cause cross presentation and cross immuno-reactions, and this may in part explain the etiology in our case.

Interestingly, thymoma is often related to autoimmune diseases $[2,3,9,12]$. In a long-term follow up (60 months) of 85 patients with thymoma, 47 patients had autoimmune 
diseases, 33 patients had MG, 4 patients had HT, and 1 patient had AIH [12].

Serum levels of TgAb and TPOAb were increased, in contrast with the decreased levels of anti-AchR-Ab during the course, suggesting that TgAb and TPOAb were not indicators for progression of HT [13]. Indeed, thyroid function had been normal during the long course, and HT did not worsen after thymectomy.

In conclusion, our long-term observation highlighted the autoimmune aspects of a patient with very rare concomitant presentation of APS-2 and AIH with thymomaassociated MG, and with bronchial asthma. Early steroid intervention and thymectomy seemed to be effective treatment. This case suggests common endocrinological and autoimmune aspects of APS-2 and AIH with thymomaassociated MG.

\section{Abbreviations \\ ACA: Adrenal cortex autoantibodies; AchR: Acetylcholine receptor; ACTH: Adrenocorticotropic hormone; AD: Addison's disease; AlH: Autoimmune hepatitis; ANA: Antinuclear antibody; APS-2: Autoimmune polyglandular syndrome type 2; HT: Hashimoto's thyroiditis; MG: Myasthenia gravis; PSL: Prednisolone; TgAb: Anti-thyroglobulin antibody; TPOAb: Anti- thyroperoxidase antibody}

\section{Acknowledgements}

The authors thank the patient and her daughter for their participation. All authors have adhered to CARE guidelines/methodology. We acknowledge proofreading and editing by Benjamin Phillis (Wakayama Medical University).

\section{Authors' contributions}

HIN, HA, HIK, CK, YU, SU, YF, YNY, and TO participated in the diagnosis and treatment of the patient, collected data, interpreted data, and wrote the manuscript. KT and SM drafted work, conducted investigations, reviewed publications, and helped in reviewing the manuscript. HIT, YNM, and TA played an important role in the management of the patient, and substantively revised the manuscript. All of the authors read and approved the final manuscript.

\section{Funding}

The study was supported by Takeda Science Foundation in the collection of data and in writing the manuscript.

\section{Availability of data and materials}

All data related to this report are stored at Wakayama Medical University (Wakayama, Japan), and are available from the corresponding author on reasonable request.

\section{Ethics approval and consent to participate}

Not applicable.

\section{Consent for publication}

Written informed consent for publication of the case was obtained from the patient. A copy of the consent form is available for review by the editor of the journal.

\section{Competing interests}

All authors (HIN, HA, HIK, CK, YU, SU, KT, YF, SM, YNY, TO, HIT, YNM, and TA) have no competing interests.

\section{Author details}

'The First Department of Medicine, Wakayama Medical University, 811-1, Kimiidera, Wakayama, Japan. ${ }^{2}$ Department of Neurology, Wakayama Medical University, 811-1, Kimiidera, Wakayama, Japan. ${ }^{3}$ Thoracic and Cardiovascular Surgery, Wakayama Medical University, 811-1, Kimiidera, Wakayama, Japan.
Received: 16 May 2019 Accepted: 24 January 2020

\section{1.}

References

1. Betterle C, Dal Pra C, Mantero F, Zanchetta R. Autoimmune adrenal insufficiency and autoimmune polyendocrine syndromes: autoantibodies, autoantigens, and their applicability in diagnosis and disease prediction. Endocr RevEndocr Rev. 2002;23(3):327-64.

2. Romi F. Thymoma in Myasthenia Gravis: From Diagnosis to Treatment. Autoimmune Dis. 2011;474512. https://doi.org/10.4061/2011/474512.

3. Mao ZF, Yang LX, Mo XA, Qin C, Lai YR, He NY, Li T, Hackett ML. Frequency of autoimmune diseases in myasthenia gravis: a systematic review. Int J Neurosci. 2011;121(3):121-9.

4. Yoshizawa K, Ota M, Katsuyama Y, Ichijo T, Matsumoto A, Tanaka E, Kiyosawa K. Genetic analysis of the HLA region of Japanese patients with type 1 autoimmune hepatitis. J HepatolJ Hepatol. 2005;42(4):578-84.

5. Asakawa H, Kashihara T, Fukuda H, Yamamoto M. A patient with thymoma and four different organ-specific autoimmune diseases. Neth J MedNeth J Med. 2002;60:292-5.

6. Konno S, Ichijo T, Murata M, Toda T, Nakazora H, Nomoto N, Sugimoto H, Nemoto H, Kurihara T, Wakata N, et al. Autoimmune polyglandular syndrome type 2 with myasthenia gravis crisis. Neurologist. 2009;15(6):361-3.

7. Ueda S, Oryoji D, Yamamoto K, Noh JY, Okamura K, Noda M, Kashiwase K, Kosuga Y, Sekiya K, Inoue K, et al. Identification of independent susceptible and protective HLA alleles in Japanese autoimmune thyroid disease and their epistasis. J Clin Endocrinol MetabJ Clin Endocrinol Metab. 2014:99(2):E379-83.

8. Horiki T, Inoko H, Moriuchi J, Ichikawa Y, Arimori S. Combinations of HLADPB1 and HLA-DQB1 alleles determine susceptibility to early-onset myasthenia gravis in Japan. Autoimmunity. 1994;19(1):49-54.

9. Müller-Hermelink HK, Marx A. Pathological aspects of malignant and benign thymic disorders. Ann MedAnn Med. 1999;31(Suppl 2):5-14.

10. Seker M, Gozu HI, Oven Ustaalioğlu BB, Sonmez B, Erkal FY, Kocak M, Barisik NO, Orbay E, Sargin M, Sargin $H$, et al. Myasthenia gravis and autoimmune Addison disease in a patient with thymoma. Clin Lung Cancer. 2009;10(5):367-70.

11. Yao Y, Zhu L, Li J, Jin Y, He L. Association of HLA-DRB1 gene polymorphism with risk of asthma: a meta-analysis. Med Sci Monit Basic ResMed Sci Monit Basic Res. 2016;22:80-6.

12. Bernard $C$, Frih H, Pasquet F, Kerever $S$, Jamilloux $Y$, Tronc F, Guibert B, Isaac $S$, Devouassoux M, Chalabreysse L, et al. Thymoma associated with autoimmune diseases: 85 cases and literature review. Autoimmun RevAutoimmun Rev. 2016;15(1):82-92.

13. Akamizu T, Amino N. Hashimoto's Thyroiditis. In: Feingold KR, Anawalt $B$, Boyce A, Chrousos G, Dungan K, Grossman A, Hershman JM, Kaltsas G, Koch C, Kopp P, et al., editors. Endotext [Internet]. South Dartmouth (MA): MDText.com, Inc; 2000-.2017.

\section{Publisher's Note}

Springer Nature remains neutral with regard to jurisdictional claims in published maps and institutional affiliations.
Ready to submit your research? Choose BMC and benefit from:
- fast, convenient online submission
- thorough peer review by experienced researchers in your field
- rapid publication on acceptance
- support for research data, including large and complex data types
- gold Open Access which fosters wider collaboration and increased citations
- maximum visibility for your research: over $100 \mathrm{M}$ website views per year
At BMC, research is always in progress.
Learn more biomedcentral.com/submissions 